\title{
INFLUENCE OF HOMEMADE AMMONIUM NITRATE AND FUEL OIL EXPLOSIVES CHARGE SHAPES ON BLAST WAVE PROPAGATION
}

\author{
L. FIGULI ${ }^{1}$, V. KAVICKY ${ }^{1}$, Z. LIGASOVÁ ${ }^{1} \&$ P. MAŇAS ${ }^{2}$, \\ ${ }^{1}$ Faculty of Security Engineering, University of Žilina, Žilina, The Slovak Republic \\ ${ }^{2}$ Faculty of Military Technology, University of Defence, Brno, The Czech Republic
}

\section{ABSTRACT}

The purpose of the paper is to investigate the influence of geometry of charges on the propagation of blast waves. Various shape charges (cylinder, sphere, irregular shape) were used in the field tests. The main type of explosive, homemade ANFO (Ammonium nitrate + fuel oil), was used as the most common used explosives in improvised explosive devices used in terrorist attacks. Characteristics of homemade and industrially made ANFO explosives are different. There were comparing charges of various types of industrially produced types of explosives and homemade explosive in the field tests. The blast wave propagation were investigated and compared.

Keywords: ammonium nitrate and fuel oil explosives, blast pressure, blast wave, blast wave propagation, field test.

\section{INTRODUCTION}

The threat of terrorism has again increased in the civilian sector over the last two years. Although terrorists are more focused on attacks using firearms and edged weapons, IED (improvised explosive devices) remain a major threat to the world. The paper is focused on the analysis of the shape of IED bombs used in bomb attacks, and the impact of various shape charges on the propagation of blast waves emerging from explosion. In the past, some studies have been made [1], but those are considering the TNT explosive and numerical simulation only. Military brisant explosives such as TNT, PETN, RDX are mainly used in areas of current conflicts (Iraq, Syria, Afghanistan, Ukraine, etc.). It is important to view the problem due to safety measures at the level of military conflict, using military standards STANAG and MIL. There is adopted legislation and control mechanisms reducing usage of such explosives (TNT, RDX, PENT) to the minimum in the civil sector and in civilized countries and therefore terrorists are resorted to use homemade explosives. Using of HMTD (Hexamethylene triperoxide diamine) or TATP (Acetone peroxide) in the amount of kilograms is technically difficult and because of these terrorists are focused on ammonium nitrate and its modification [2].

Scientific research pays very little attention to such explosives. The theory is generally based on the results of TNT and the next prediction. In the view of safety measures setting, it seems like a very general, unrealistic way. In our work, we are therefore focused on the comparison of results obtained in the measurement of TNT and RDX and homemade explosive on the basis of AN (Ammonium nitrate). Given the fact that in homemade explosive, there are many variables (quality of ammonium nitrate, mixing quality, density, porosity of AN, water molecules in the material, etc.), we tried to create the most authentic type of a charge and not 
to keep idealized theoretical procedures. Regarding the charge shape, in the real world, there is not a prerequisite of a compact spherical charge and its central initiation, but there is not the assumption that it could be considered as a linear charge, that is, the ratio of width and length is greater than five. In a real situation, the charge shape is different and is adjusted to IED packaging (sports bag, suitcase, vest, or distributed in the vehicle). It is closer to a spherical charge. Therefore, we chose a spherical charge with the 20 grams of initiatory plastic explosives to guarantee that in this way prepared charges will be detonated.

\section{FIELD TESTS}

The field tests were focused on the measurement of the overpressures of different types and shapes of charges. The set of field tests took place at the development and testing set of the Ministry of Defence of the Slovak Republic called Military Technical and Testing Institute Zahorie. They were realised in 2014. Methodology of the measurement is based on [3]. The explosive charge was positioned at a wooden base in the height of $1.6 \mathrm{~m}$ over the ground, that is, in the height of human chest. Sensors were placed in the distances of 2 meters from the source (see Fig. 1) in the four directions perpendicular to themselves. Maximum overpressure was measured using blast pressure sensors type 137A23 and 137A24 PCB Piezotroics. An orientation of all sensor tips was towards the epicentre of the explosions. Besides maximum overpressure, the velocity of blast wave and the level of noise were also measured. The send surface of the field test area was without the roughness.

\subsection{Type of explosive}

There were used different types of explosive in the field tests. As a verification charge, TNT explosive was used. Two types of homemade ANFO explosives (pure ammonium nitrate and ammonium nitrate with fuel oil) and two types of standard industrially made explosive (RDX, PETN) were used. Explosive charges were about the same weight $980 \mathrm{~g}+20 \mathrm{~g}$ ignition explosive PLNp10. Unfortunately, from 13 tests only 8 were recorded completely in all four directions. The record of overpressure from PETN was not recorded.

\subsection{1 $\mathrm{TNT} \mathrm{C}_{6} \mathrm{H}_{2}\left(\mathrm{NO}_{2}\right)_{3} \mathrm{CH}_{3}$}

TNT is one of the most commonly used explosives for industrial, military, and mining applications. It is yellow-coloured solid chemical compound [4].

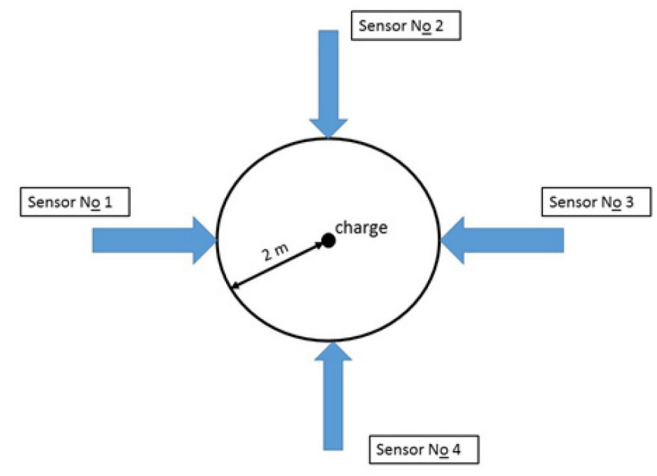

a) Displacement

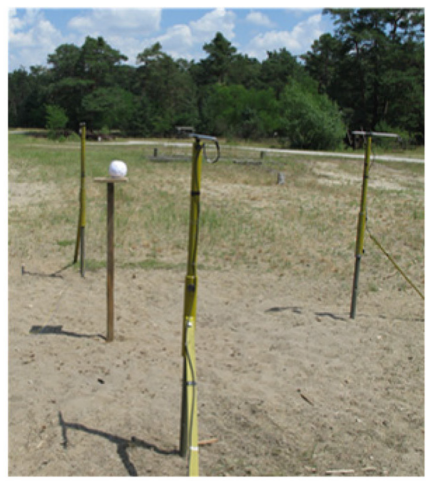

b) Real situation

Figure 1: Positions of blast pressure sensors in the field test. 


\subsection{2 $\mathrm{RDX} \mathrm{C}_{3} \mathrm{H}_{6} \mathrm{~N}_{6} \mathrm{O}_{6}$}

It is an explosive nitroamine. Its chemical name is cyclotrimethylenetrinitramine. In its synthesized state, RDX is a white, crystalline solid. RDX is considered one of the most powerful and brisant of the military high explosives. It is obtained by reacting white fuming nitric acid (WFNA) with hexamine, producing dinitromethane and ammonium nitrate as byproducts [5].

\subsubsection{ANFO $\mathrm{NH}_{4} \mathrm{NO}_{3}+$ oil $+\mathrm{Al}(\mathrm{Mg})$}

Is a widely used bulk industrial or homemade explosive mixture. The mixture of ANFO is made from GPN HD Ammonitrate 33.5 (composed of 33.5\% of ammonium nitrate - $16.7 \%$ of nitric nitrogen and 16.8\% of ammoniacal nitrogen) and fuel oil Extra M2T (5\% of charge weight) (Fig. 2) were used for the preparation of ANFO explosives for the blast tests.

Characteristics and the represented type of explosive are in Table 1. Characteristics of homemade ANFO were set and the explosive pressure were set according [6].

\subsection{Shape of charges}

Three different shapes of charges were used in the field test: block, cylinder and sphere. Used explosives cannot be formed to the exact desired shape because it is a bulk material. Therefore, the paper cylinders and spheres were made to ensure the most probable shape of charges. Neither to cylinder charge a length/width ratio was not exceed, and it is greater than five; therefore they cannot be regarded as a linear charge. It is assumed the blast wave propagation

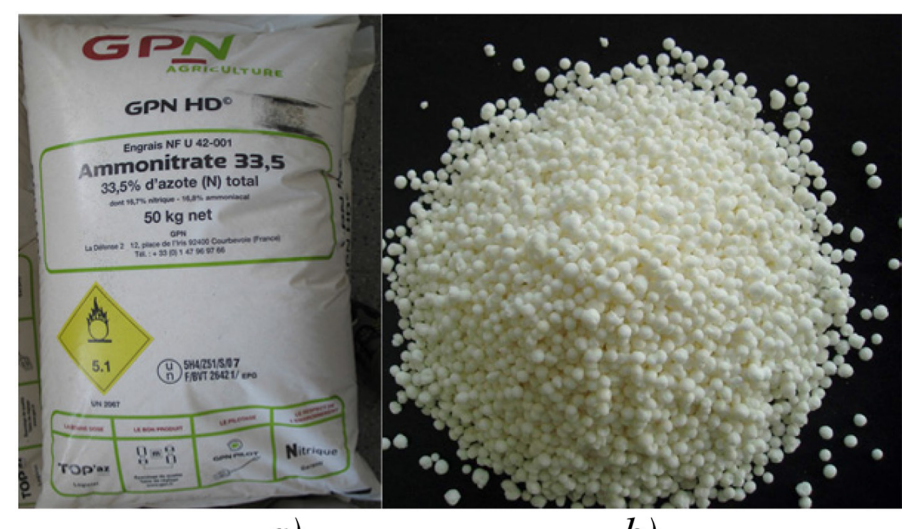

a)

b)

Figure 2: Ammonium nitrate used in field tests (a) sack (b) prills.

Table 1 Characteristics of industrially made ANFO explosives.

\begin{tabular}{llll}
\hline Explosive & $\begin{array}{l}\text { Explosive detonation } \\
\text { velocity }[\mathrm{m} / \mathrm{s}]\end{array}$ & Density $\left[\mathrm{g} / \mathrm{cm}^{3}\right]$ & $\begin{array}{l}\text { Explosive } \\
\text { pressure }[\mathrm{GPa}]\end{array}$ \\
\hline TNT & 6,800 & 1.58 & 18.4 \\
RDX & 8,750 & 1.83 & 34.7 \\
ANFO & 1,829 & 0.84 & 0.71 \\
\hline
\end{tabular}




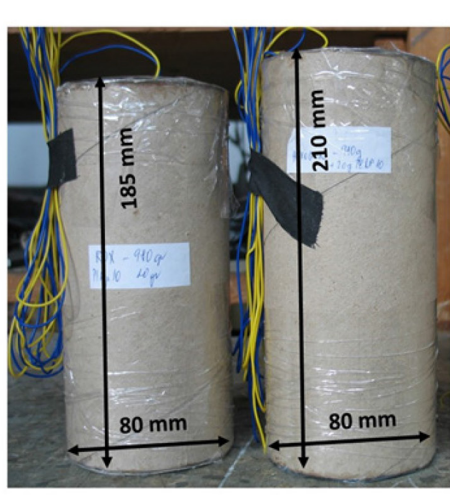

a) RDX

b) ANFO

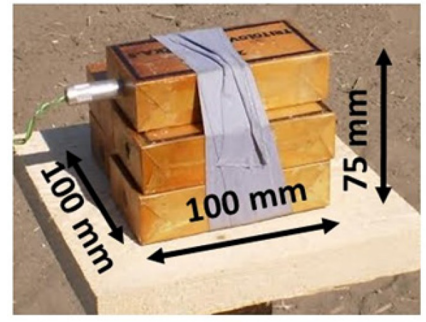

c) TNT

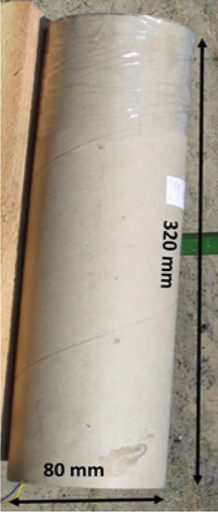

c)Ammonium nitrate

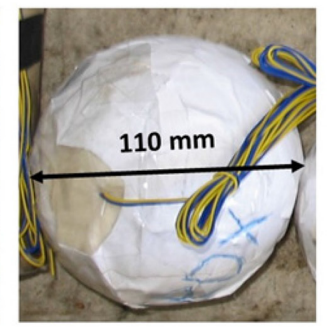

d) RDX. PETN

Figure 3: Dimension of used charge shapes.

to all directions equally. An explosive material was wrapped in a cardboard cover made just for field test not to influence the resultant value of overpressure.

There were various ways of position of fuse according to the explosion charge shape.

\subsubsection{Cube}

The TNT charge was composed from the 5 of 200 grams charges. A fuse and ignition explosive PLNp10 was imbedded in the top $200 \mathrm{~g}$ charge (Fig. 3), but not in the precise geometrical centre.

\subsubsection{Cylinder}

The fuse was inserted in one of endings. Fuse setting was oriented to the sensor No 2 in the case of asymmetrical initiation. Cylinders were tested in horizontal positions.

\subsubsection{Sphere}

The fuse and ignition explosive PLNp10 was imbedded centrally after the explosion pouring to the half of volume of covering and repeatedly poured to the required weight (free space in the top part of sphere was filled by cotton wool and glued). Just as it was possible, was guaranteed the initiation from the geometric centre of the charges.

\subsection{Experimental results}

Set of 13 explosion tests was done: one cubic charge of TNT, two cylindrical charge of pure Ammonium Nitrate, four cylindrical charge of ANFO, three cylindrical charge of RDX, two 
spherical charge of RDX and one spherical charge of PETN. Unfortunately, from 13 tests only 8 were recorded completely in all four directions and only three type of the explosive material. The records of overpressure from PETN and pure ammonium nitrate were not recorded. In the case of pure ammonium nitrate, there was an uncompleted detonation of the explosive and the part of ammonium nitrate prills was spread in the environment in the radius of $3.5 \mathrm{~m}$ from the explosive source. Propagation of blast wave in all four directions can be seen in Fig. 4. The detailed results for the security reasons are appropriate for release in the public domain in the conference.

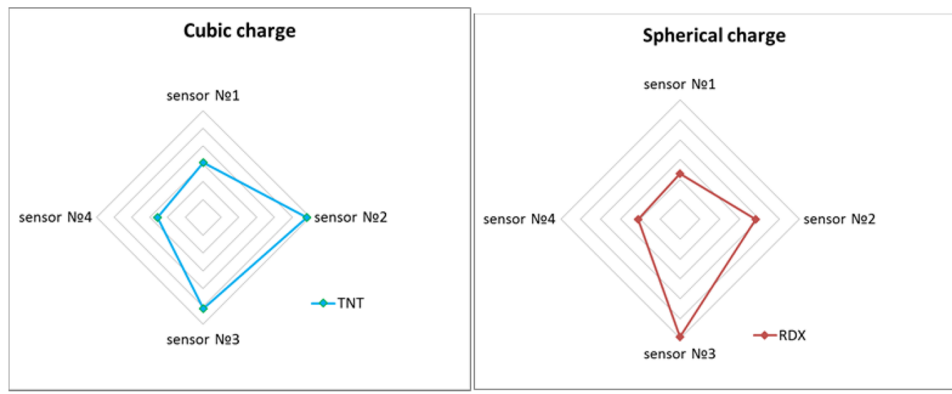

a)

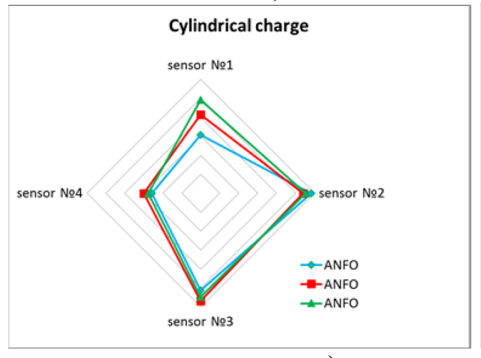

c) b)

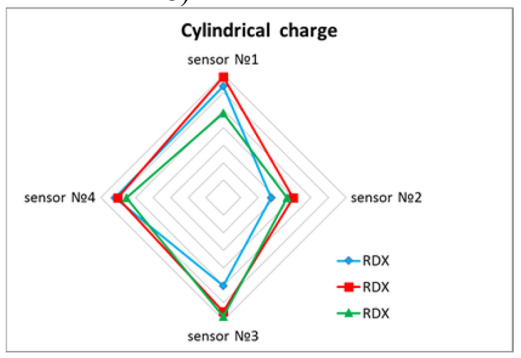

d)

Figure 4: Maximal recorded overpressures in all four direction for (a) cubic charge (TNT), (b) spherical charge (RDX), (c) cylindrical charge (ANFO) and (d) cylindrical charge (RDX).

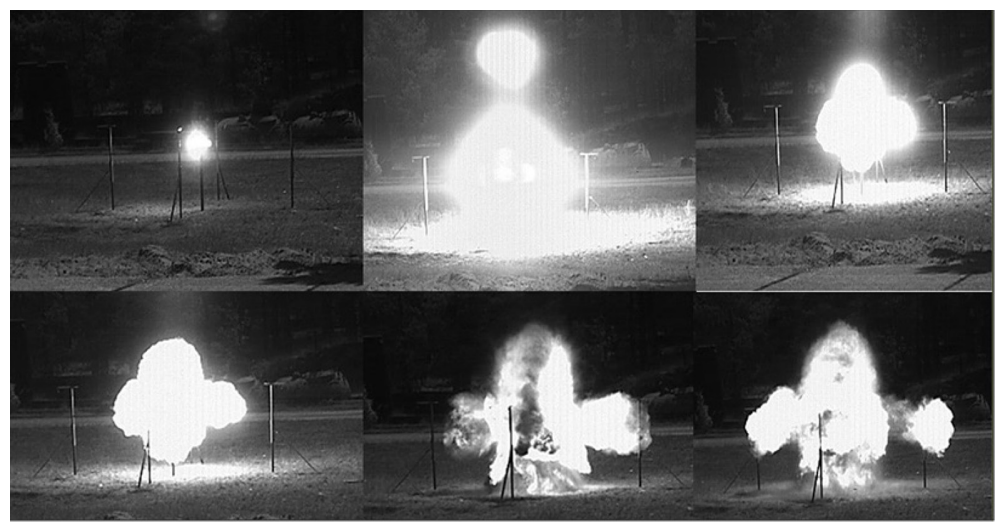

Figure 5: Propagation of blast wave from the field test. 
Explosion and blast wave propagation were recorded using high-speed camera in the concrete shelter $40 \mathrm{~m}$ distant from the explosive charge. The propagation of blast wave can be seen in Fig. 5.

\section{SIMULATION OF BLAST WAVE PROPAGATION}

\subsection{Analytical simulation}

Estimations of peak overpressure due to spherical blast are based on scaled distance. The "cube root law" says that if the detonation of two charges made from same material, in the same form but with different weight occurs in the same atmosphere, this phenomenon generates similar blast waves in the same scaled distance. The scaled distance is expressed as $\mathrm{Z}=\mathrm{R} /$ $\mathrm{W}^{1 / 3}$, where $R$ is the actual effective distance from the explosion expressed in meters and $W$ is weight of charge in kilograms. In our former research [7], we have compounded a set of new relationships for the determination of peak overpressure. There is used an assumption of the dependence of explosive pressure and density of explosives. The relationship for the overpressure in the distance $\mathrm{R}$ for $1 \leq \mathrm{Z} \leq 10$ has been modified to this form (Kavicky-Figuli model):

$$
P_{+}=\left(\frac{0,202}{Z}+\frac{0,224}{Z^{2}}+\frac{1,182}{Z^{3}}\right) \cdot 0,5 e^{0,035 R}
$$

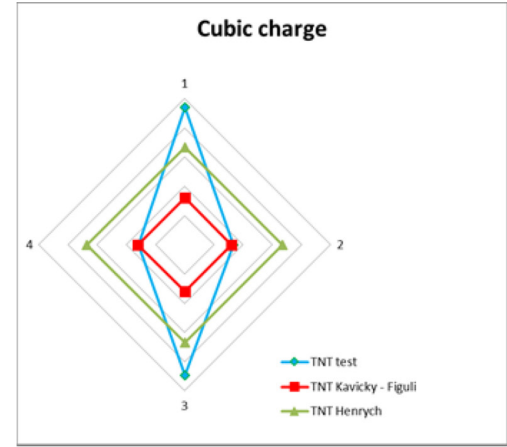

a )

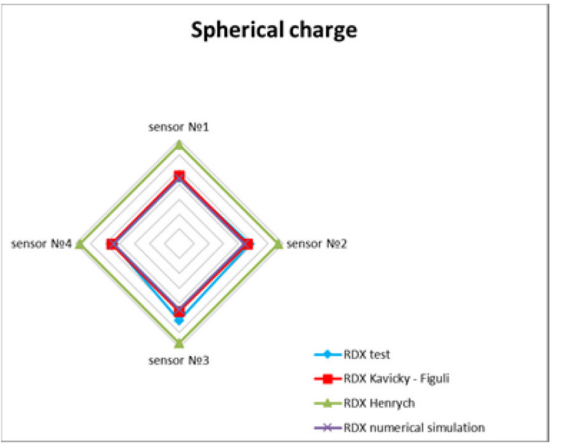

b)

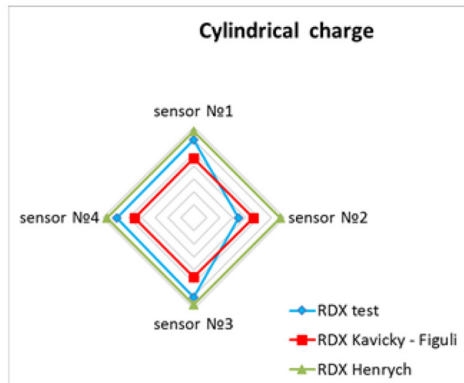

c)

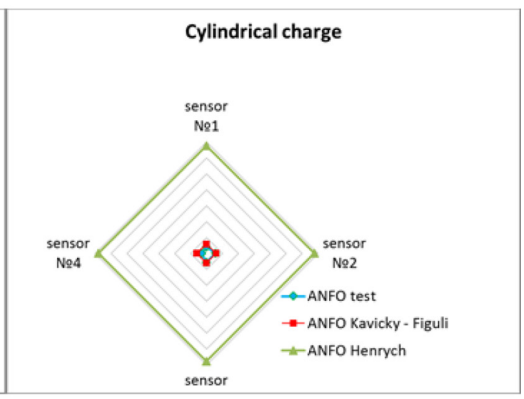

d)

Figure 6: Comparison of recorded and set overpressures in all four direction for (a) cubic charge (TNT), (b) spherical charge (RDX), (c) cylindrical charge (RDX) and (d) cylindrical charge (ANFO). 


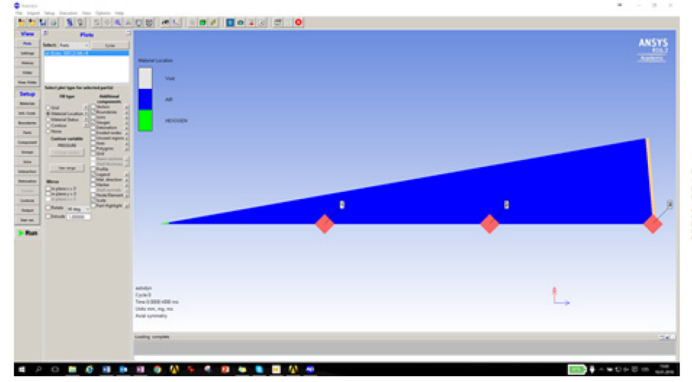

a )

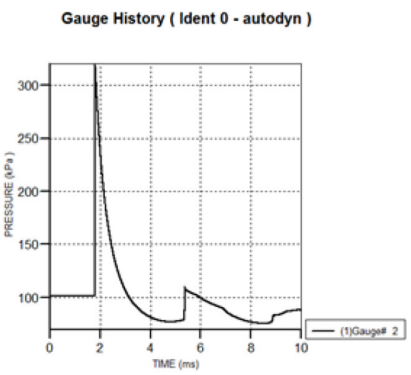

b)

Figure 7: (a) Numerical model of spherical RDX charge, (b) Pressure - Time chart for gauge at $2 m$ distance.

The peak overpressures were set using above-mentioned formula. The values of measured and set overpressures (according the other relationship [8]) are seen in Fig. 6.

\subsection{Numerical simulation}

Numerical simulations were conducted in ANSYS/AUTODYN v. 16 software and as an initial step, 1D simulation with wedge elements were used. The advantage of this approach is time efficiency and simplicity of results (see an example in Fig. 7). The material properties for the air and explosives were used from AUTODYN material library. This approach expects only air blast of spherical shape charge with detonation point on centre. The next step will be full 3D simulation with respect to real shape of charge and reflection from terrain, but it is not possible to model discontinuity in filling of cardboard enclosure (container) which can be source of differences from experimental results.

\section{CONCLUSIONS}

It can be predicted from the values of blast pressure and the behaviour of the detonation during the testing of homemade explosives - ANFO, the process of deflagration or incomplete detonation was only done during the measurement. Despite this, the resulting pressures did not significantly differ from mathematical approach being for the safety management a significant positive finding. The perpetrator of such act might not have explosives prepared perfectly, but pure nitrate or explosive prepared unprofessionally is sufficient to reach the objectives for him, the values are lower than the mathematically calculated using different methods of various authors.

Regarding charge shape, we tried to create a homogeneous charge of spherical shape as a wright shape, but it was not possible to do it perfectly. Different values of pressure during an explosion of imperfect spherical and free filled irregular shape charge are negligible from the point of assessing a safety level. In reality, no perpetrator even criminal or terrorist act exactly produces spherical-shaped charges. If he/she places a charge in a form of a bag by the mistake ( in opposite side), due to the stress condition, it can cause that the effect will be instead strong, minimal one. This fact is solvable technically, in a simple way with more certainty orientation of explosion. For safety reasons, this fact will not be described in this paper.

The differences in the results of mathematical and measured values can be affected by the fact that the place of sensors placing, that is, $2 \mathrm{~m}$ from the explosion, there is after reflection created Mach's wave rising from the ground to the sensor level. This distance was chosen in 
direct proportion to the charge as the most dangerous place of damage or personal injury with the emphasis on the overpressure vector sum. Although there is the sum of vectors of two overpressures, measured values are significantly not different from standardly set values. It is therefore evident that used formulas from physics explosion are, for the safety level and risk of persons and facilities assessing, adequate and appropriate. For standard explosives, the most appropriate formulas, that is, Henrych's, for ANFO explosives “Kavicky - Figuli" formula is approaching to the values of overpressures. Convenience of the use of relationship depends on the evaluation of environmental conditions (in the environment with an easy access to military explosives should be chosen formula of Henrych, in the environment, where it is significantly difficult to obtain sufficient military explosives, "Kavicky - Figuli" formula).

In the area of simulations, it is possible to focus on the evaluation of time history of blast pressure, especially the duration of the overpressure and vacuum phase. It is also possible to evaluate the pressure profile in the greater distance from the source of blast when the Mach wave will be fully formed, and the results should be more relevant to the pressure profile in ground blast.

It is also planned to do a $3 \mathrm{D}$ numerical simulation for the comparison of measurements.

\section{ACKNOWLEDGEMENT}

STV GDROUP a.s., Hvězdova 1716/2b, 14078 Praha 4 - Nusle, Czech Republic, www. stvgroup.cz

\section{REFERENCES}

[1] Cai, J., Tang, T. \& Ma, J., Influence of charges on a closely air blast loading. Applied Mechanics and Materials, 217-219, pp 1411-1415, 2012. http://dx.doi.org/10.4028/www.scientific.net/AMM.217-219.1411

[2] Kavický, V., Jangl, Š. \& Gašpierik, L., Terorizmus hrozba doby. Citadella, Bratislava, 2015.

[3] ITOP 4-2-822: Electronic Measurement of Airblast Overpressure and Impulse Noise, 2000.

[4] Jangl, Š. \& Kavický, V., Ochrana pred účinkami výbuchov výbušnín a nástražných výbušných systémov. Oščadnica: Jana Kavická-KAVICKY, 2012.

[5] Luo, K.-M., Lin, S.-H., Chang, J.-G. \& Huang, T.-H. Evaluations of kinetic parameters and critical runaway conditions in the reaction system of hexamine-nitric acid to produce RDX in a non-isothermal batch reactor, 2002.

[6] SHARMA, P.D., Presentation, Online. http://www.slideshare.net/ sharmapd1/an-anfohanfo.

[7] Kavický, V., Figuli, L. Jangl, S. \& Ligasová, Z., Analysis of the field test resultsof ammonium nitrate: fuel oil explosives as improvised explosive device charges. WIT Transactions on the Built Environment, 141, pp. 297-309, 2014. http://dx.doi.org/10.2495/SUSI140261

[8] Henrych, J., The Dynamics of Explosion and its Use. Elsevier Scientific Publishing Company: Amsterdam and New York, 1979. 